\title{
Effects of Soil Temperature on Microsclerotia of Calonectria ilicicola and Soybean Root Colonization by this Fungus
}

P. U. Kuruppu, Parks Library, Iowa State University, Ames 50011; R. W. Schneider, Department of Plant Pathology and Crop Physiology, Louisiana State University Agricultural Center, Baton Rouge 70803; and J. S. Russin, Department of Plant and Soil Science, Southern Illinois University, Carbondale 62901-4415

\begin{abstract}
Kuruppu, P. U., Schneider, R. W., and Russin, J. S. 2004. Effects of soil temperature on microsclerotia of Calonectria ilicicola and soybean root colonization by this fungus. Plant Dis. 88:620-624.

Field soil artificially infested with laboratory-produced microsclerotia of Calonectria ilicicola was incubated for $1,2,3$, or 6 weeks at $20,25,30,35$, and $40^{\circ} \mathrm{C}$. These temperatures approximate soil temperatures that were measured in soybean fields during the growing season in south Louisiana. Germinable microsclerotia were enumerated after incubation at different temperatures, and soybean seeds were planted in these soils. After 8 weeks, percent root colonization was determined as a measure of infectivity of microsclerotia. Results showed that soil temperature is a critical factor in survival of microsclerotia. The optimal soil temperature range for survival of microsclerotia was 20 to $30^{\circ} \mathrm{C}$, and the maximum soil temperature limit was $35^{\circ} \mathrm{C}$, above which microsclerotia did not survive. Effects of temperature on soybean root colonization were examined in growth chambers by growing soybean plants in soil infested with laboratorygrown microsclerotia for 4 weeks after seed germination. Maximum infection of young soybean roots by $C$. ilicicola occurred between 25 and $30^{\circ} \mathrm{C}$ but decreased with increasing temperatures and was negligible at $40^{\circ} \mathrm{C}$. According to these results, soil temperature is a critical environmental factor controlling the development of red crown rot in soybeans in Louisiana. These findings suggest that, if red crown rot is a threat, soybean planting time should be based on soil temperature rather than calendar dates.
\end{abstract}

Red crown rot of soybean (Glycine max (L.) Merr.) was reported in Louisiana in 1976 and soon was recognized as an important disease in that state (4). The causal agent of red crown rot is the soilborne fungus Calonectria ilicicola Boedijn \& Reitsma $(6,13,24)$. C. ilicicola, previously known as $C$. crotalariae $(6,13)$, is the perfect stage of Cylindrocladium parasiticum, previously known as Cylindrocladium crotalariae $(6,13)$. In 1966, Bell and Sobers (2) determined that this fungus is the causal agent of black root rot, also known as Cylindrocladium black rot, of peanut. The fungus produces both conidia and ascospores, but roles for these spores in the red crown rot disease cycle are not known. Microsclerotia serve as survival and dispersal structures, and they persist several years in soil and on host debris (2).

Berner et al. (4) and Russin et al. (25) reported that delays in planting reduce incidence of red crown rot. Recommended disease management strategies in Louisiana include delayed planting and use of

Corresponding author: R. W. Schneider

E-mail: rschnei@LSU.edu

Accepted for publication 18 December 2003.

Publication no. D-2004-0405-02R

(C) 2004 The American Phytopathological Society less susceptible cultivars $(3,4)$, but delayed planting is the management strategy of choice for red crown rot because of the lack of resistant cultivars. However, the mechanism responsible for reduced disease incidence following delayed planting is not clear. Plants may escape the most conducive field conditions for root colonization by the pathogen, or the number of infective microsclerotia may decline in response to increasing soil temperature, or both phenomena may occur. Phipps and Beute (20) and Sidebottom and Beute (26) reported that soil temperature is an important environmental factor influencing the development of black root rot of peanut. The effect of temperature on soybean root colonization by $C$. ilicicola has not been investigated.

Disease severity in susceptible and resistant peanut cultivars depends on inoculum density (ID) of microsclerotia in soil $(9,20)$. Consequently, factors that affect survival of microsclerotia may be critical for development of black root rot in peanut eral reports showed that ID of C. ilicicola in peanut fields is fully or partially controlled by temperature and soil moisture, and seasonal as well as diurnal fluctuations in these two factors could influence propagule survival, which in turn may affect the incidence and severity of black root rot of peanut $(1,8,18,20,21)$. Kuruppu as well as red crown rot in soybean. Sev- et al. (14) recorded a substantial decrease in $C$. ilicicola populations in soil along with reduced soybean root colonization in the field following an unusually warm summer (14). It was suggested that high soil temperature affects not only pathogen survival but also soybean root colonization by this fungus (14). The objectives of this study were to determine the effects of temperature on survival of microsclerotia in a heavy alluvial soil and on soybean root colonization by $C$. ilicicola. We chose to eliminate soil moisture as a variable in these studies by maintaining a constant soil moisture regime across all soil temperature treatments.

\section{MATERIALS AND METHODS}

Soil for all experiments was collected from the Ben Hur Research Farm of the Louisiana State University Agricultural Center close to Baton Rouge, in a field with no history of red crown rot. The soil type was Mhoon silty clay loam (13). Soil samples from the area were assayed using the procedure described below for the presence of $C$. ilicicola, and the red crown rot pathogen was not detected. Soil was stored in plastic bins until used.

Inoculum production and assay. Isolate SG 915 of $C$. ilicicola (11) was grown on potato dextrose agar (PDA) at $25^{\circ} \mathrm{C}$ for 6 weeks. Mycelia with microsclerotia in agar were blended in distilled water for 1 min at low speed in a commercial laboratory blender. The slurry was poured through nested sieves of $425 \mu \mathrm{m}$ over 150 $\mu \mathrm{m}$ pore size. Material on the $150-\mu \mathrm{m}$ sieve was washed under a stream of water to dislodge and remove hyphal fragments. Microsclerotia then were suspended in distilled water, enumerated, and mixed with soil.

Following soil infestation, microsclerotia were enumerated according to the following procedure. Soil (200 g) was blended with $100 \mathrm{ml}$ of water at low speed, and the suspension was poured through nested sieves of $150 \mu \mathrm{m}$ over $45 \mu \mathrm{m}$ pore size. Material on the $45-\mu \mathrm{m}$ sieve was washed with water to make a suspension and then mixed with $\mathrm{NaOCl}(0.25 \%)$ for $30 \mathrm{~s}$. This suspension was poured through a $45-\mu \mathrm{m}$ sieve, and the material collected on the sieve was combined with $200 \mathrm{ml}$ of water. One milliliter of this suspension was added to $100 \mathrm{ml}$ of modified Phipps medium (14) that had been autoclaved and 
cooled to $50^{\circ} \mathrm{C}$ then poured into five petri plates ( $9 \mathrm{~cm}$ diameter). Plates were incubated for 7 to 10 days at room temperature ( 25 to $27^{\circ} \mathrm{C}$ ), at which time the number of colonies in all five plates was determined. A $50-\mathrm{g}$ portion of the soil sample was dried at $105^{\circ} \mathrm{C}$ for $48 \mathrm{~h}$ to determine soil moisture content. Inoculum density was expressed as number of microsclerotia per gram of oven dry soil.

Germination of microsclerotia on culture media. The effects of temperature on germination of microsclerotia and subsequent colony formation were determined in a laboratory study. Microsclerotia were collected as described above, transferred singly to the center of PDA plates and incubated at $20,25,30,35$, and $40^{\circ} \mathrm{C}$. These temperatures were selected because they represent the range of soil temperatures in Louisiana soybean fields during the growing season. Each treatment was replicated six times, and colony diameters were measured after 7 days. The experiment was conducted twice.

Germinability of microsclerotia in soil. The term "germinability" refers to the ability of microsclerotia to produce colonies on agar media after recovery from soil. Germinability of microsclerotia was assessed by the number of colonies per gram of soil produced on PDA. Field soil was infested with microsclerotia of $C$. ilicicola isolate SG 915 that were produced in the laboratory on PDA. A soil infestation level of 90 microsclerotia per gram of soil was used to ensure sufficient root colonization at all incubation temperatures. Soil $(1 \mathrm{~kg})$ was placed in individual closed but perforated plastic bags and infested with $C$. ilicicola microsclerotia as described earlier. The amount of water to be added to bring this soil to field capacity was predetermined and was added to soil in plastic bags. Soils in plastic bags were incubated at $20,25,30,35$, and $40^{\circ} \mathrm{C}$ in darkness for 1, 2, 3, or 6 weeks. Soil moisture was maintained at field capacity during incubation by adding sufficient water to each bag to bring it back to its initial weight every 2 days. Each temperature treatment was replicated five times. At the end of each incubation period, the number of germinable microsclerotia in soil incubated at each temperature was assayed using the method described above. This experiment was conducted twice.

Infectivity of microsclerotia in soil. The term "infectivity" refers to the ability of microsclerotia to germinate and colonize soybean roots. Infectivity of microsclerotia was assessed by determining the percentage of soybean roots colonized from plants grown in infested soil preincubated at different temperatures for different durations. Seeds of the susceptible soybean cultivar Sharkey were planted in $12-\mathrm{cm}$ diameter plastic pots (one seed per pot) containing this soil. Each treatment was replicated five times. Plants were grown in a greenhouse $\left(25 \pm 5^{\circ} \mathrm{C}\right)$ and were harvested after 8 weeks. To assay colonization of soybean roots by $C$. ilicicola, root systems were first freed from soil by gentle washing under a stream of water. Taproots and lateral roots were separated and cut into segments $1 \mathrm{~cm}$ in length, and 20 taproot and 50 lateral root segments were selected at random. These root segments were surfacesterilized in $0.25 \% \mathrm{NaOCl}$ for $30 \mathrm{~s}$, rinsed three times in sterile water, and blotted on sterile filter paper. Root segments then were plated on modified Phipps medium (14) and incubated at room temperature $\left(25\right.$ to $27^{\circ} \mathrm{C}$ ) under continuous fluorescent light for 10 to 14 days. Root colonization was expressed as percentage of segments from which colonies of $C$. ilicicola were recovered. Soil population levels were assayed again at the end of the experiment using the methods described above. This experiment was conducted twice.

Data were analyzed using the General Linear Models procedure of SAS (SAS
Institute, Cary, NC). Main and interactive effects of temperature and duration on germinability and infectivity of $C$. ilicicola microsclerotia were determined. Treatments were compared using least squares means.

Effects of temperature on root colonization. The effect of temperature on soybean root colonization by $C$. ilicicola was assessed in growth chambers using a photoperiod of $14 \mathrm{~h}$ fluorescent light and $10 \mathrm{~h}$ darkness. Day temperatures were 20, 25, 30,35 , and $40^{\circ} \mathrm{C}$, and night temperatures were $5^{\circ} \mathrm{C}$ cooler in each treatment. A single temperature regime was assigned to each growth chamber. Approximately $2 \mathrm{~h}$ were required for soil and air temperatures to equilibrate following the diurnal temperature changes. Soil was infested with microsclerotia to achieve infestation densities of 40, 80, and 120 microsclerotia per gram of soil, as described previously. Each inoculum level was replicated five times. A single, pregerminated seed of the suscepti-

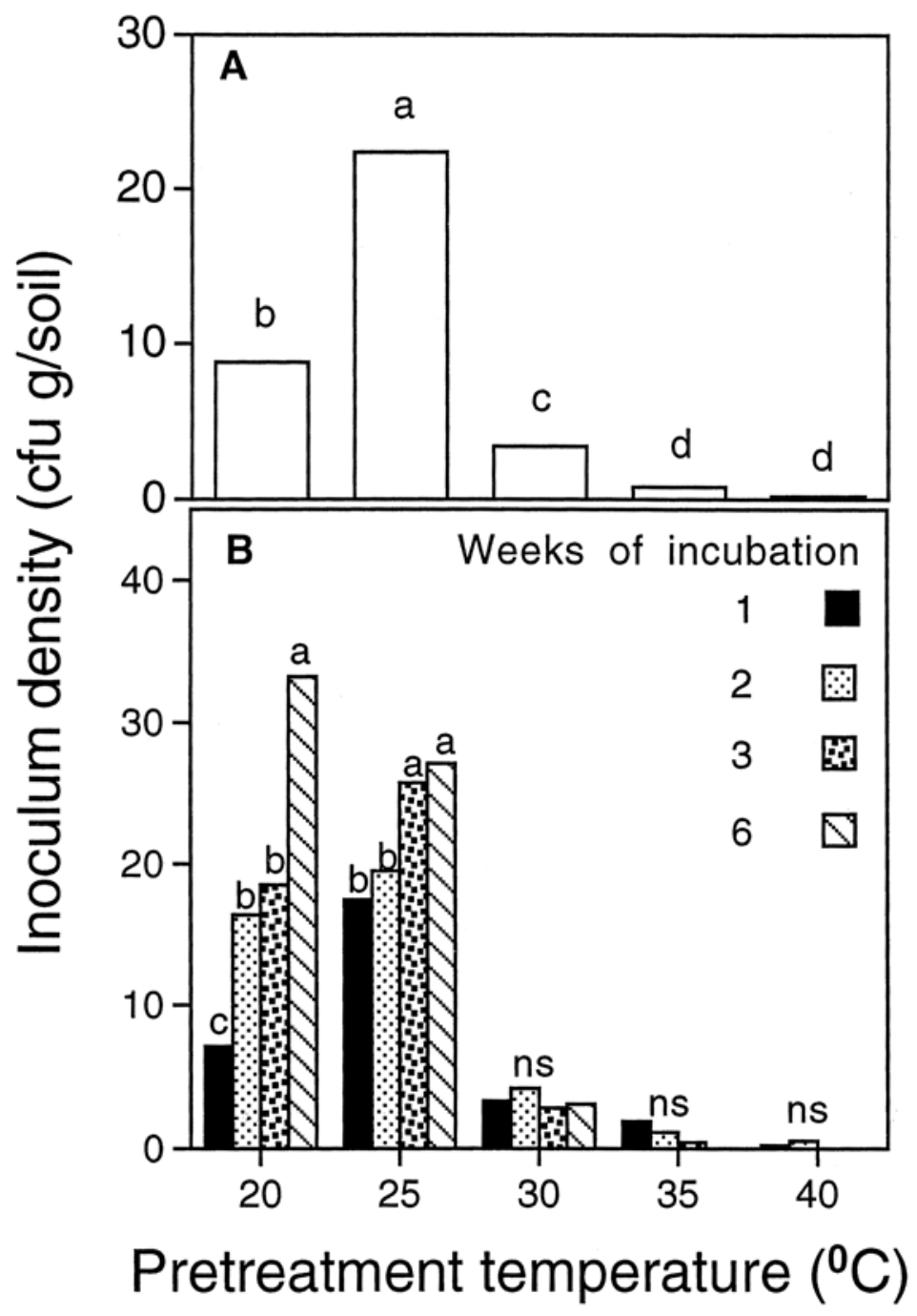

Fig. 1. Relationships between temperature and incubation time on inoculum density of Calonectria ilicicola. Bars represent inoculum density of C. ilicicola after incubation of infested soil for 1,2,3, or 6 weeks at $20,25,30,35$, or $40^{\circ} \mathrm{C}$ : $\mathbf{A}$, inoculum densities across all incubation durations, and $\mathbf{B}$, effect of incubation durations on inoculum. Treatment means marked with the same letter are not significantly different at each temperature $(P \leq 0.05)$ according to a least squares means analysis. 
ble soybean cultivar Sharkey was planted in infested soil in 10-cm-diameter plastic pots, which were watered to field capacity once each day. Plants were harvested after 4 weeks, and the percentage of tap and lateral root segments colonized was determined using the method described above. This experiment was conducted twice. Data were analyzed using the General Linear Models procedure of SAS to determine the main and interactive effects of temperature and inoculum density on soybean root colonization by $C$. ilicicola. Treatments were compared using least squares means.

\section{RESULTS}

Germination of microsclerotia on culture media. Laboratory-produced microsclerotia of $C$. ilicicola germinated and produced colonies on PDA at 20, 25, 30, and $35^{\circ} \mathrm{C}$. Colony diameter increased with increasing temperatures from $4.8 \mathrm{~cm}$ at $20^{\circ} \mathrm{C}$ to $9.8 \mathrm{~cm}$ at $30^{\circ} \mathrm{C}$. Maximum growth occurred at $30^{\circ} \mathrm{C}$, and a further increase in temperature to $35^{\circ} \mathrm{C}$ reduced colony growth to $9.5 \mathrm{~cm}$. Microsclerotia did not germinate at $40^{\circ} \mathrm{C}$ and did not germinate when transferred from 40 to $25^{\circ} \mathrm{C}$.

Germinability of microsclerotia in soil. Germinability of $C$. ilicicola microsclerotia was very sensitive to incubation temperature. When averaged across all incubation durations, germinability decreased steadily as incubation temperature increased (Fig. 1A). Few microsclerotia germinated after incubation at $35^{\circ} \mathrm{C}$ or above (Fig. 1A). At lower incubation temperatures $\left(20\right.$ or $25^{\circ} \mathrm{C}$ ), the number of germinable microsclerotia increased as the incubation duration increased, but incubation duration did not have a significant effect on germinability as temperature was increased to $30^{\circ} \mathrm{C}$ or above (Fig. 1B).

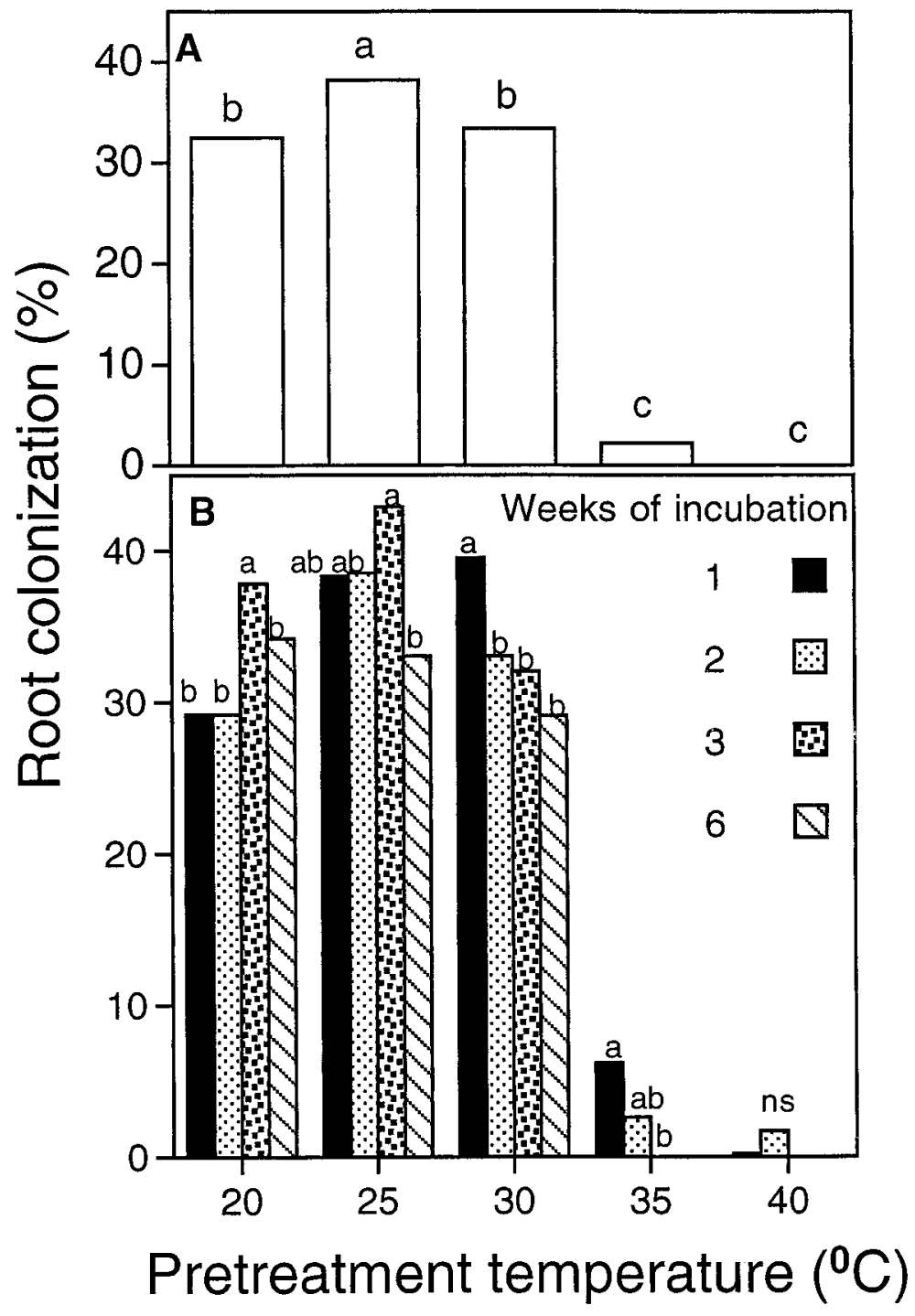

Fig. 2. Root colonization by Calonectria ilicicola in soybeans grown at $25^{\circ} \mathrm{C}$ for 8 weeks in a greenhouse soil infested with 90 microsclerotia per gram of soil. Soils were previously incubated at 20, 25, 30,35 , or $40^{\circ} \mathrm{C}$ for $1,2,3$, or 6 weeks. Bars represent: $\mathbf{A}$, root colonization percentages across all incubation durations, and $\mathbf{B}$, the effect of incubation duration on root colonization. Treatment means marked with the same letter at different temperatures did not differ significantly $(P<0.05)$ according to least squares means.

Infectivity of microsclerotia in soil. The highest infectivity across all four incubation temperature regimes occurred at $25^{\circ} \mathrm{C}$ (Fig. 2A). Infectivity of microsclerotia previously exposed to 20,25 , and $30^{\circ} \mathrm{C}$ was higher (between 32.5 and $38.2 \%$ ) than that of microsclerotia exposed to 35 and $40^{\circ} \mathrm{C}$. Infectivity was negligible for microsclerotia exposed to $40^{\circ} \mathrm{C}$. There were differences in infectivity depending on duration of incubation at each temperature (Fig. 2B). Maximum infectivity of microsclerotia exposed to 20 and $25^{\circ} \mathrm{C}$ was observed at 3 weeks, and infectivity of microsclerotia decreased significantly when exposed to 30 and $35^{\circ} \mathrm{C}$ for longer than 1 week. The effect of duration of exposure on infectivity in microsclerotia was insignificant when exposed to $40^{\circ} \mathrm{C}$.

Effect of soil temperature on root colonization. Both taproot and lateral root colonization increased as day temperatures increased from 20 to $30^{\circ} \mathrm{C}$, but they decreased significantly with further increases in day temperature (Fig. 3A and B). Maximum taproot colonization occurred at 25 to $30^{\circ} \mathrm{C}$ (Fig. 3A), and maximum lateral root colonization occurred at $30^{\circ} \mathrm{C}$ (Fig. 3B). Lateral root colonization levels were lowest $(<2 \%)$ at 20,35 , and $40^{\circ} \mathrm{C}$. With regard to taproot colonization, the interaction of temperature and soil inoculum level was not significant $(F=0.77, P=0.6323)$. There was no detectable root colonization at $40^{\circ} \mathrm{C}$ at 40 and 80 microsclerotia per gram of soil, but at 120 microsclerotia per gram of soil there was $8.7 \%$ taproot colonization. Similarly, with lateral root colonization, there was no interaction between temperature and inoculum level $(F=0.45$, $P=0.8916)$.

\section{DISCUSSION}

Early root colonization by $C$. ilicicola is critical for the development of red crown rot disease in soybean (14). Kuruppu et al. (14) showed that there is a positive relationship between ID of $C$. ilicicola and soybean root colonization. Therefore, the initial pathogen inoculum level in soil appears to be an important factor in red crown rot development in soybean. Reduction of initial soil inoculum level through cultural and chemical methods is recommended for black root rot management in peanut $(19,26)$, and temperature is the most important environmental factor affecting ID of $C$. ilicicola in peanut soils $(8,18,20)$. However, studies of soil temperature effects on the survival of $C$. ilicicola in peanut soils were focused on low temperature limits $(8,23)$ and extreme winter temperature effects (23). Kuruppu et al. (14) suggested that soil temperature plays a very important role in reducing populations of $C$. ilicicola in soil, thereby reducing red crown rot incidence in soybean. It was suggested that soil temperatures during the summer can be high enough to inhibit germinability and infec- 
tivity of microsclerotia of C. ilicicola in the heavy alluvial soils in soybean fields in Louisiana (14). The present study examined this possibility.

Reports of temperature effects on microsclerotia of $C$. ilicicola used the terms "survival", "viability", and "germinability" interchangeably to refer to production of fungal colonies on nutrient media after recovering microsclerotia from soil $(5,7,8,12,18,22,23,26)$. In this study, we consider germinability to be the ability of microsclerotia to germinate and produce colonies on nutrient agar. Our results showed that germinability of microsclerotia of $C$. ilicicola does not necessarily reflect their ability to infect soybean roots. The optimal soil temperature range for the maintenance of infectivity of microsclerotia, i.e., ability to germinate in the rhizosphere and infect soybean roots, was established in this study. Although the number of germinable microsclerotia was considerably reduced when infested soil was exposed to $30^{\circ} \mathrm{C}$ for 1 to 6 weeks, root colonization levels in soybeans grown in this soil were as high as those grown in soil incubated at the optimal temperature range $\left(20\right.$ to $\left.30^{\circ} \mathrm{C}\right)$ for germinability. These results suggest that the loss of germinability caused by incubating soil at $30^{\circ} \mathrm{C}$ could have been a temporary effect in some microsclerotia and that germinability could be regained if microsclerotia were exposed to a lower temperature for several weeks. Roth et al. observed a temporary loss of germinability caused by low temperatures $\left(-10^{\circ} \mathrm{C}\right.$ or $6^{\circ} \mathrm{C}$ for 4 weeks) $(23)$. In their study, the low temperature effect was partially alleviated when soil incubated at low temperatures was transferred to $25^{\circ} \mathrm{C}$ for 4 weeks, which suggested that low temperature does not always cause a permanent loss of germinability in C. ilicicola. We showed that soil temperature above $35^{\circ} \mathrm{C}$ affected not only germinability but also infectivity of these microsclerotia. The high temperature limit for survival of microsclerotia of $C$. ilicicola was $35^{\circ} \mathrm{C}$, in that exposure to temperatures $>35^{\circ} \mathrm{C}$ for a period as short as 1 week substantially reduced the number of viable microsclerotia in soil.

Recoverable levels of microsclerotia of C. ilicicola were reduced considerably when incubated in soil at all temperatures used in our study. Loss of germinability of sclerotia of Sclerotium rolfsii and Macrophomina phaseolina during incubation in soil also was reported $(10,17)$. Reduction of germinability and pathogenic aggressiveness during incubation in soil of some of these fungal propagules was attributed to loss of their endogenous nutrient reserves resulting from respiration and diffusive stress imposed by other soil microorganisms competing for carbon substrates $(10,16,27)$. In our study, the number of germinable microsclerotia increased when incubated in soil at 20 and $25^{\circ} \mathrm{C}$, the opti- mal temperature range. Apparently, the temporary quiescent state imposed on these microsclerotia by exposure to soil was alleviated with time at temperatures favorable for the fungus.

Microsclerotia used in this study were produced on nutrient media in the laboratory. Linderman and Gilbert (15) suggested that sclerotia of Sclerotium rolfsii produced in cultures may be structurally and physiologically different from those produced in soil. Therefore, conclusions regarding the behavior of microsclerotia in the field based on information obtained from laboratory-produced microsclerotia must be viewed with caution. Nevertheless, based on these findings, we are now able to explain the inconsistencies in IDs of $C$. ilicicola in soybean fields subjected to delayed planting in 1994, 1995, and 1996 as reported by Kuruppu et al. (14). In that field study, soil temperatures exceeded the optimal range for germinability $\left(>30^{\circ} \mathrm{C}\right)$ during late spring and reached the maximum limit for pathogen survival $\left(35^{\circ} \mathrm{C}\right)$ during early summer in 1995 . Soil temperatures were above the limit for this pathogen for nearly 9 weeks. Results from the present study also show that even in the presence of high inoculum densities, lateral root colonization was negligible and taproot colonization was reduced to a very low level as the temperature was increased above $30^{\circ} \mathrm{C}$. In the field, root colonization was very low early in the summer of 1995 , even though inoculum density was relatively high, but soil temperature was above $30^{\circ} \mathrm{C}$ (14). The number of viable microsclerotia in the field as well as root colonization during the summers of 1995 and 1996 were low (14). This can now be clearly attributed to high temperatures

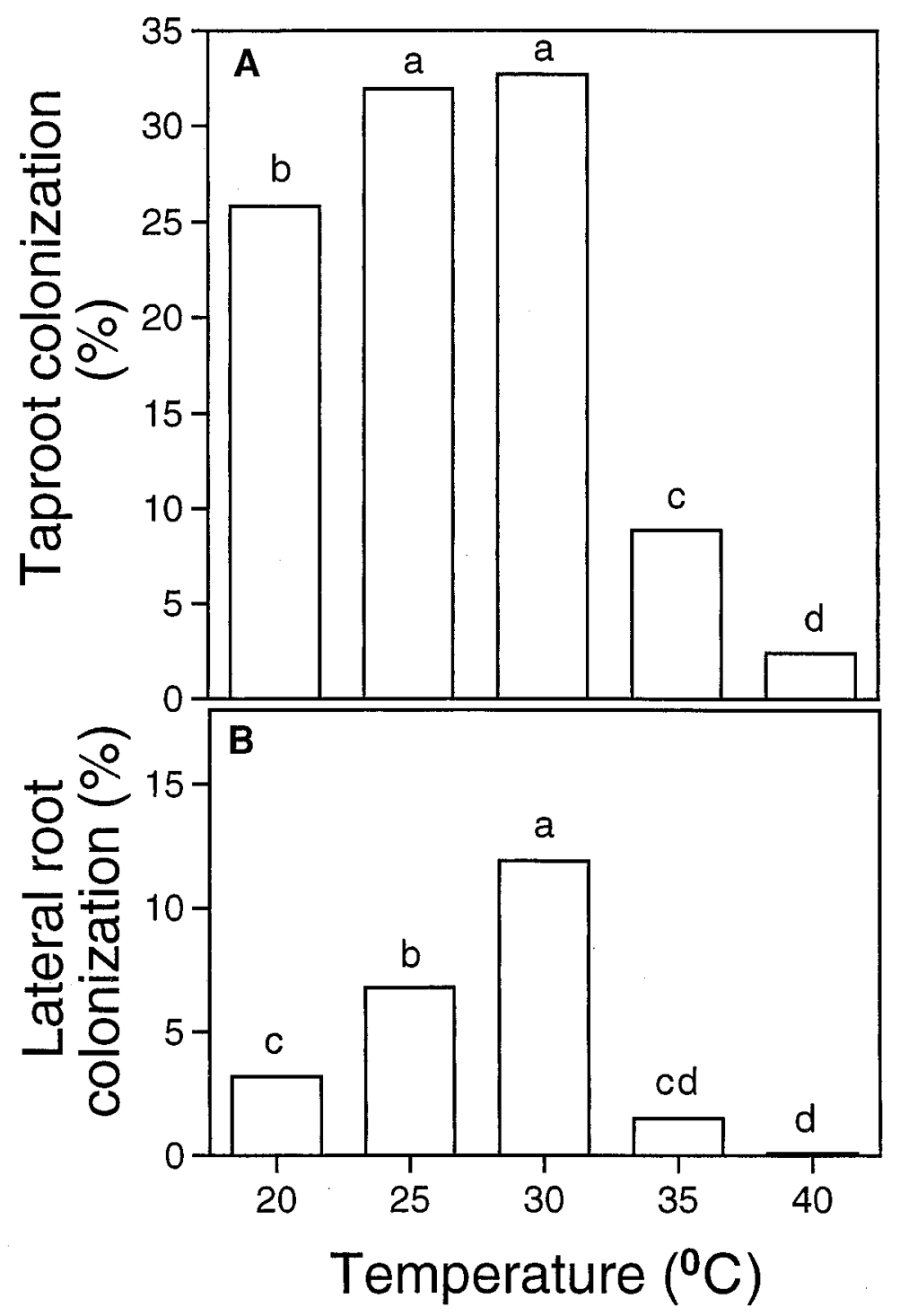

Fig. 3. Taproot and lateral root colonization of soybean by Calonectria ilicicola. Plants were grown in soil inoculum densities of 40,80 , and 120 microsclerotia per gram of soil at $20,25,30,35$, and $40^{\circ} \mathrm{C}$ day soil temperatures $\left(15,20,25,30\right.$, and $35^{\circ} \mathrm{C}$ night soil temperatures, respectively). Bars represent temperature effects on $\mathbf{A}$, taproot colonization and $\mathbf{B}$, lateral root colonization across all inoculum densities. Treatment means marked with the same letter at different temperatures did not differ significantly $(P \leq 0.05)$ according to a least squares means analysis. 
during the two growing seasons. While we cannot rule out the possible interactions of soil moisture, the effects of soil temperature alone are sufficient to explain our findings in the field.

Soil temperature was reported to be the most important environmental factor affecting the infection of peanut roots by $C$. ilicicola (2,20). Our findings established the optimal soil temperature for $C$. ilicicola to colonize soybean seedling roots. We showed that this fungus was not able to colonize soybean roots at $40^{\circ} \mathrm{C}$ when soil inoculum density was low. However, the fact that a low level of root colonization was detected at this temperature at the highest ID indicates that when ID is very high, there can be a few surviving microsclerotia in soil. These surviving microsclerotia may be able to infect soybean roots and cause disease if subsequent environmental conditions are conducive for root colonization.

An examination of average soil temperatures during the soybean growing season in Louisiana shows a short period (a few weeks) during early summer when soil temperatures are conducive $\left(20\right.$ to $\left.30^{\circ} \mathrm{C}\right)$ to soybean root colonization by $C$. ilicicola (14). Our previous work demonstrated the importance of early soybean root colonization for development of red crown rot later in the season (14). We now show that if soybeans are planted when soil temperatures are conducive for the pathogen, there will be more early root colonization resulting in the development of more severe red crown rot symptoms later in the season. Our findings from this and the previous study (14) strongly suggest that, if red crown rot is a threat, time of planting should be based on soil temperature rather than calendar dates.

\section{LITERATURE CITED}

1. Bell, D. K. 1967. Effects of soil temperature and plant age on the severity of Cylindrocladium rot of peanut. Plant Dis. Rep. 51:986988.

2. Bell, D. K., and Sobers, E. K. 1966. A peg, pod, and root necrosis of peanuts caused by a species of Calonectria. Phytopathology 56:1361-1364.

3. Berggren, G. T., Jr., and Snow, J. P. 1989. Red crown rot. Pages 44-45 in: Compendium of Soybean Diseases. 3rd ed. J. B. Sinclair and P. A. Backman, eds. American Phytopathological Society, St. Paul, MN.

4. Berner, D. K., Berggren, G. T., Snow, J. P., and White, E. P. 1988. Distribution and management of red crown rot of soybean in Louisiana. Appl. Agric. Res. 3:160-166.

5. Black, M. C., and Beute, M. K. 1984. Relationships among inoculum density, microsclerotium size, and inoculum efficiency of Cylindrocladium crotalariae causing root rot of peanuts. Phytopathology 74:1128-1132.

6. Crouse, P. W., Wingfield, M. J., and Alfenas, A. C. 1993 Cylindrocladium parasiticum sp. nov., a new name for $C$. crotalariae. Mycol. Res. 97:889-896.

7. Diomande, M., and Beute, M. K. 1981. Relation of Meloidogyne hapla and Macroposthonia ornata populations to Cylindrocladium black rot in peanuts. Plant Dis. 65:339-342.

8. Griffin, G. J., Roth, D. A., and Powell, N. L. 1978. Physical factors that influence the recovery of microsclerotium population of $\mathrm{Cyl}$ indrocladium crotalariae from naturally infested soils. Phytopathology 68:887-891.

9. Harris, N. E., and Beute, M. K. 1982. Histological responses of peanut germplasm resistant and susceptible to Cylindrocladium crotalariae in relationship to inoculum density. Phytopathology 72:1250-1256.

10. Hyakumachi, M., and Lockwood, J. L. 1989. Relation of carbon loss from sclerotia of Sclerotium rolfsii during incubation in soil to decreased germinability and pathogenic aggressiveness. Phytopathology 79:1059-1063.

11. Kim, K. D. 1994. Susceptibility in soybean to red crown rot and characteristics of virulence in Calonectria crotalariae. Ph.D. diss. Louisiana State University, Baton Rouge.

12. Krigsvold, D. T., Griffin, G. J., and Hale, M. G. 1982. Microsclerotia germination of Cylindrocladium crotalariae in the rhizospheres of susceptible and resistant peanut plants. Phytopathology 72:859-883.

13. Kuruppu, P. U. 1998. Factors affecting root colonization by Calonectria ilicicola and development of red crown rot disease on soybean. Ph.D. diss. Louisiana State University, Baton Rouge.

14. Kuruppu, P. U., Schneider, R. W., and Russin, J. S. 2004. Factors affecting soybean root colonization by Calonectria ilicicola and development of red crown rot following delayed planting. Plant Dis. 88:613-619.
15. Linderman, R. G., and Gilbert, R. G. 1972 Behavior of sclerotia of Sclerotium rolfsii produced in soil or in culture regarding germination stimulation by volatiles, fungistasis, and sodium hypochlorite treatment. Phytopathology 63:500-504.

16. Mondal, S. N., Kageyama, K., and Hyakumachi, M. 1995. Germinability, viability, and virulence of chlamydospores of Fusarium solani $\mathrm{f}$. sp. phaseoli as affected by the loss of endogenous carbon. Phytopathology 85:12381244

17. Papavizas, G. 1977. Survival of sclerotia of Macrophomina phaseolina and Sclerotium cepivorum after drying and wetting treatments. Soil Biol. Biochem. 9:343-348.

18. Pataky J. K., and Beute, M. K. 1983. Effects of inoculum burial, temperature, and soil moisture on survival of Cylindrocladium crotalariae microsclerotia in North Carolina. Plant Dis. 67:1379-1382.

19. Phipps, P. M. 1990. Control of Cylindrocladium black rot of peanut with soil fumigants having methyl isothiocyanate as the active ingredient. Plant Dis. 74:438-441.

20. Phipps, P. M., and Beute, M. K. 1977. Influence of soil temperature and moisture on the severity of Cylindrocladium black rot in peanut. Phytopathology 67:1104-1107.

21. Phipps, P. M., and Beute, M. K. 1979. Population dynamics of Cylindrocladium crotalariae microsclerotia in naturally infested soil. Phytopathology 69:240-243.

22. Phipps, P. M., Beute, M. K., and Barker, K. R. 1976. An elutriation method for quantitative isolation of Cylindrocladium crotalariae microsclerotia from peanut field soil. Phytopathology 66:1255-1259.

23. Roth, D. A., Griffin, G. J., and Graham, P. J. 1979. Low temperature induces decreased germinability of Cylindrocladium microsclerotia. Can. J. Microbiol. 25:157-162.

24. Rowe, R. C. Beute, M. K., and Wells, J. C. 1973. Cylindrocladium black rot of peanuts in North Carolina. Plant Dis. Rep. 57:387-389.

25. Russin, J. S., Troxclair, N. N., Jr., Boethel, D. J., and McGawley, E. C. 1985. Effect of soybean planting date and soil nutrients on incidence of red crown rot and populations of insects associated with roots. (Abstr.) Phytopathology 75:1284.

26. Sidebottom, J. R., and Beute, M. K. 1989. Control of Cylindrocladium black rot of peanut with cultural practices that modify soil temperature. Plant Dis. 73:672-676.

27. Sneh, B., and Lockwood, J. L. 1976. Quantitative evaluation of the microbial nutrient sink in soil in relation to the model system for soil fungistasis. Soil Biol. Biochem. 8:65-69. 